\title{
Knowledge, attitude and practice level of women at the periconceptional period: a cross-sectional study in Shaanxi China
}

Danyang $\mathrm{Li}^{1 \dagger}$, Liyan Huang ${ }^{1 \dagger}$, Wenfang Yang ${ }^{1,2^{*}}$, Cuifang $\mathrm{Qi}^{1}$, Li Shang ${ }^{1}$, Juan Xin ${ }^{1}$, Lingxia Zeng ${ }^{3}$, Min Zhang ${ }^{3}$, Hui Song ${ }^{4}$ and Mei Chun Chung ${ }^{2,1}$

\begin{abstract}
Background: Identifying and understanding the knowledge, attitude and practice (KAP) level of women at the periconceptional period has implications for formulating and measuring the adverse pregnancy outcomes for primary prevention.

Methods: A cross-sectional study among pregestational and pregnant women was conducted in Shaanxi during 2016-2017.

Results: Among 791 participants, the average score of periconceptional healthcare knowledge awareness was $6.32 \pm 1.78$, whereas $28.8 \%$ of women have failed. Women who planned to or had undergone premarital and pre-pregnancy examinations accounted for 50.2 , and $62.5 \%$, respectively. Less than half (42.0\%) of the women started taking folic acid (FA) before pregnancy, and only $37.9 \%$ of them took FA regularly at the right time. Multivariate analysis showed that age was the main factor influencing the Attitude and Practice level of women at the periconceptional period, and demonstrated a positive effect on the awareness of right timing of folic acid supplementation, and high rates of premarital and pre-pregnancy examinations. Also, the knowledge pass rate was increased with education level. Fewer women who have birth experience were willing to take FA consistently at the right time compared to those women without birth.
\end{abstract}

Conclusions: The women at the periconceptional period in Shaanxi lacked the total KAP level of periconceptional healthcare, especially those who live in rural areas and have less education. Government agencies should reinforce more effective primary preventive measures and policies for the prevention of adverse pregnancy outcomes.

Keywords: KAP level, Periconceptional period, Cross-sectional study, Shaanxi China

\section{Background}

Adverse pregnancy outcomes are significant health challenges for women in the periconceptional period as well as infants. These include pregnancy bleeding, hypertensive disorders and sepsis, which lead to more than half of the maternal deaths [1]. It is estimated that about 14.9 million preterm infants are born every year, accounting for $11.1 \%$ live births, and more than

\footnotetext{
* Correspondence: yang.wendy@163.com

${ }^{\dagger}$ Danyang Li and Liyan Huang contributed equally to this work.

'Department of Obstetrics and Gynecology, The First Affiliated Hospital of

Xi'an Jiaotong University, Xi'an, Shaanxi, People's Republic of China

${ }^{2}$ Department of Public Health and Community Medicine, Tufts University

School of Medicine, Boston, Massachusetts, USA

Full list of author information is available at the end of the article
}

half of them are born in Asian and African countries including China [2]. The mortality rate of infants and children under the age of 5 in China was significantly lower in eastern and urban areas compared with midwestern and rural areas [3]. A cross-sectional survey of a large sample of Shaanxi Province revealed that the incidence of adverse pregnancy outcomes was $25.45 \%$, which was higher than the national average level [4]. According to the government data on birth defects in the Shaanxi province, the prevalence in the last ten years showed a steady rate and did not decline with time (Additional file 1: Table S1). After several years of government efforts to promote folic acid (FA) supplementation in pregnant women, the

(C) The Author(s). 2019 Open Access This article is distributed under the terms of the Creative Commons Attribution 4.0 International License (http://creativecommons.org/licenses/by/4.0/), which permits unrestricted use, distribution, and 
prevalence of neural tube defects (NTDs) in China has been decreased from $11.40 \%$ in 2000 to $5.74 \%$ in 2010 and $2.81 \%$ in 2014, and its rank in birth defects remained stable in the top 10 [5]. The NTDs are also considered as the main reason for birth defects in developed countries [6].

Therefore, it is necessary to adopt preventive measures to control and relieve the occurrence of these diseases. Primary prevention including specific practices of health promotion, protective procedures, detection and regulation of environmental pollutants is considered as an essential way for adverse pregnancy outcomes remission. Previous studies have demonstrated that about $70 \%$ of adverse pregnancy outcomes such as birth defects are effectively prevented or cured with proper care [7]. One critical step for the primary prevention practice is to investigate the knowledge, attitude and practice (KAP), which mainly evaluates the understanding and grasping of knowledge, attitude and expectation as well as related behaviours of the participants. It is confirmed that KAP interacted with each other. This survey was conducted based on the principle that increasing knowledge results in changing attitudes and practices to minimise disease burden [8]. Some practices can be accepted before knowledge increase and attitude change to alter people's awareness of diseases and their physical condition and reduce the number of diseases and social burden [9]. Understanding the KAP level remains helpful to identify the knowledge gap and determine behaviours of the public to further plan and implement for the prevention of adverse pregnancy outcomes.

Scientific evidence has demonstrated that some risk factors and protective factors such as FA [10] and micronutrient supplementation [11] were correlated with adverse. FA supplementation during the periconceptional period has been started to popularise since the 1990s in China to reduce adverse pregnancy outcomes, especially the birth defects. According to a previous study that focused on the preventive knowledge of FA in Shanghai, more than half of the people did not understand the role of FA, and only one-third of the women knew the right time for taking FA [12]. However, in Israel and America, the number of women with the knowledge of FA roles $(80.8 \%$ \& $74 \%)$ and the right time to take folic acid supplements $(74.6 \%$ \& 55\%) are higher than Shanghai $[13,14]$. The rate of FA regular usage in Shaanxi (11.2\%) was more upper than Korea $(10.3 \%)$ but lower than Japan (85\%) [15-17].

Also, premarital, pre-pregnancy and prenatal examinations are the three routine inspections recommended for women at the periconceptional period to ensure the health of both mothers as well as children and the examination results are directly related to the adverse pregnancy outcomes [18]. In China, the number of women at the periconceptional period undertaking routine examinations and participation in the awareness programs of pre-pregnancy health in public is still quite limited compared to developed countries [19].

Since 2009, the provincial government of Shaanxi decided to give away free FA supplements $(0.4 \mathrm{mg} / \mathrm{d})$ to all the women at the periconceptional period through the Family Planning System and Maternal and Child Health Care System. At the same time, the government switched their attention from secondary and tertiary prevention to primary prevention. After the implementation of government policies, attention has been paid on understanding and actions of primary prevention of adverse pregnancy outcomes in public, especially in women at the childbearing age. It is necessary to investigate the attitudes and behaviours of the society about the current policies as well as to provide evidence for the local government for formulating the priority targets and providing recommendations on the current actions regarding the primary prevention in Shaanxi. Hence, a cross-sectional study aiming at women at the periconceptional period was conducted in 2016-2017 to investigate the women's eugenic KAP level on adverse pregnancy outcomes as primary prevention.

\section{Material and methods Study objects}

From October 2015 to February 2017, 791 women were gathered in Yan 'an and $\mathrm{Xi}$ 'an, Shaanxi province, respectively. Eligible women were who prepared to pregnant in 3 months or at the duration of pregnancy, and lived in the local area for more than 1 year. For the participants from Yan'an, a stratified, random sampling method was used. Women who met the requirements were randomly selected from four counties (Baota, Ansai, Yanchang, Ganquan) out of thirteen counties. They were approached through the periconceptional healthcare lectures that we conducted in each selected county, which assisted by the Yan'an Health Committee. For participants in Xi'an, they were randomly selected from women who attended physical examinations in the First Affiliated Hospital of Xi'an Jiaotong University. Women were identified by asking the question that "Are you now in pregnant?" and "Do you have any plans for pregnancy in the latest three months?" into pre-pregnant and pregnant groups. The informed consent form was obtained from each participant and their phone numbers and residential addresses were recorded.

\section{Study content and survey methods}

Women were investigated and questioned by one-to-one interviews. The questionnaire was formulated by experts of family planning. All questions assessed the KAP level of women at the periconceptional period regarding 
periconceptional healthcare, including basic social demographic characteristics of the participants (age, location, education background for women and their husbands, average monthly family income, and pregnancy history); knowledge level on periconceptional health care (Knowledge section); the participation and demands of pre-pregnancy and prenatal examination (Attitude section), and FA taking compliance (Practice section).

The survey of KAP three sections has been completed at the time of recruitment for women who have been pregnant for more than 3 months. For women who were preparing for pregnancy and who have been pregnant but less than 3 months, only two parts of the survey, Knowledge and Attitude sections, have been completed at the time of recruitment. A Follow-up survey was conducted to investigate folic acid use during the 3 months before pregnancy (at the first prenatal examination) and the first trimester of pregnancy (at the $13-16^{+6}$ weeks' prenatal examination). Finally, A total of 791 valid questionnaires were obtained for the survey of Knowledge and Attitudes sections, of which 643 were obtained for complete folic acid supplementation information, due to $97(12.23 \%)$ women who were preparing for pregnancy but were not pregnant, 51 (6.45\%) women were lost to follow-up during pregnancy.

In terms of Knowledge part, 10 closed choice questions were designed aiming at the essential knowledge points of periconceptional healthcare such as the concept, and categories of birth defects, FA supplementation time and the importance of prenatal examination (details are shown in Additional file 2: Table S2). Except for the question "classification of birth defects" was multiplechoice, the remaining nine were single-choice questions. For the "classification of birth defects", we listed four most common birth defects for choices: anencephaly, hydrocephalus, cleft lip and palate, and congenital heart disease, and asked women to tick off the conditions they considered as birth defects. It was considered as classified correctly if all four options had been selected, missing or not selected were classified incorrectly. For the remaining nine single-choice questions, only one of the options was correct. For example, the question in terms of "the importance of prenatal examinations" was that "All my examinations before pregnancy were normal, do I need to have prenatal examinations?" The answer was "Yes, because the pre-pregnancy examinations cannot take the place of prenatal examinations", and the rest of the options were "No, because many items have been checked before pregnancy, it is enough to guarantee a healthy baby"; "Not necessarily required, prenatal examination is only necessary if there is a problem in prepregnancy check" and "Have no idea". Closed quantify scoring system was used for the 10 questions, where 1 question corresponded to 1 point. When the score was higher than or equal to 6, it was defined as knowledge pass.

For the attitude level, the participation rate of the prepregnancy and premarital examination was investigated as the women's attitude of periconceptional healthcare. Participation of regular examinations in this research was defined as women who planned to participate or had participated in the premarital examination and prepregnancy examination. The practice part was represented by FA taking. "FA taking every day" was defined as taking pills containing at least $0.4 \mathrm{mg}$ FA every day without interruption during 3 months before pregnancy or the first trimester of pregnancy.

\section{Statistical analysis}

After data cleaning and quality check, all data were coded, and Epidata3.1 was used for data entry and logic error detection. Quantitative data were described as mean \pm standard deviation, and categorical data were presented by rates or composition ratio. In terms of knowledge related to periconceptional health care, there were 10 questions in total. Each received one point for the correct answer of each item, and the score ranged from 0 to 10 points. After averaging the scores of all participants, the overall average score of the knowledge level was obtained. Presentation of all tables was executed by using Microsoft Excel 2010. Differences in the knowledge level, participation rate of regular examinations and FA taking were used as dependent variables to represent KAP level. Different demographic characteristics, such as women's region, age, location, educational background, and family income, were regarded as independent variables. Bivariate analysis such as ANOVA and $X^{2}$ test and multivariate logistic regression analysis were used to evaluate the influence of social demographic characteristics on KAP level. All data were analyzed by SPSS 20.0. $P<0.05$ was considered as statistical significance.

\section{Ethical statement}

This research was approved by the Ethics Committee of Science of Medical center, The First Affiliated Hospital of Xi'an Jiaotong University (No:XJTU1AF2017LSK-45). The written informed consent form was obtained from each participant who took part in this survey.

\section{Results}

Basic characteristics of women at the periconceptional period

A total of 791 women at the periconceptional period finished our interview, which included 451 from Yan'an (located in the north of Shaanxi) and 340 from Xi'an (located in the middle part of Shaanxi). Among these interviews, the average age of the women was $28.42 \pm$ 3.99 (with a maximum of 45 and a minimum of 19). The 
main age group was 26-30 years old, which accounted for $56.1 \%$. The proportion of women living in city and suburb/rural areas was 72.0 and $28.0 \%$, respectively. In all families, almost half of the women and their husbands were graduated from senior high school/college, and about $35.3 \%$ of them were undergraduates or above. Only $19.7 \%$ women and $21.3 \%$ of husbands were from junior high school or below. The family income ranged from 4000 to $12,000 \mathrm{RMB}$, accounting for $53.9 \%$. $16.9 \%$ of women preparing for pregnancy, while $83.1 \%$ of them already had pregnancy during the investigation time, and $69.6 \%$ of them had no pregnancy experience at all (Table 1).

\section{Knowledge level and bivariate analysis}

The results from Table 2 indicated that the average knowledge level score of 791 women was $6.32 \pm 1.78$, wherein $28.8 \%$ of women failed, and their average score was below 6 points. Most of the women acquired 7 points (20.4\%), but only 10 women got full score. Besides, the importance of prenatal examination showed the highest awareness according to these 10 knowledge points, reaching $90.1 \%$. Most of them lacked knowledge of the dosage of folate intake (8.6\%).

With increasing age of the women, the rate of knowledge transfer and the common knowledge were increased obviously among the participants. Women aged $>35$ obtained the highest average score (6.96 \pm $1.83)$, women $<25$ years acquired the least average score $(5.48 \pm 1.74)$. In addition to the concept of birth defects, primary prevention, FA supplementary time and dosage, and neonatal screening showed significant differences in the average knowledge and overall knowledge passing rate among women of different ages. The average score and passing rate of women living in suburb/rural areas were significantly lower than those women living in cities, especially for women's pre-pregnancy examination, FA supplementary time and dosage, the importance of prenatal examination as well as high-risk pregnancy. With the improvement of the educational background of both women and their husbands, the knowledge level was promoted as well. Except for the concept of primary prevention, the passing rates of other questions were also increased significantly in women with higher education. Moreover, increased family income facilitated women's knowledge level apart from birth defects and primary prevention. However, pregnancy history showed no influence on the overall knowledge level of women at the periconceptional period, and the results were shown in Table 2.

\section{Attitude and practice level and bivariate analysis}

In terms of regular examinations, the proportion of 791 women who planned to participate or had participated in the premarital examination and pre-pregnancy check were 50.2 and $62.5 \%$, respectively. The participation rate in the premarital examination was significantly lower than the pre-pregnancy check $\left(\chi^{2}=221.215\right.$, $P<0.001)$. In terms of FA use, majority of the women (94.2\%) took FA during their pregestational and gestational periods, but less than half $(42.0 \%)$ of the women started taking FA before pregnancy. There were $81.6 \%$ of women who insist on taking FA every day. However, only $37.9 \%$ of participants took FA regularly at the right time (Table 1).

From Table 2, it could be seen that the increase of family income significantly reduced the participation of premarital and pre-pregnancy examinations. Meanwhile, in terms of the right time to start taking folic acid, different factors including women's age, location, education of both women and their husband, and family income demonstrated apparent effects on FA use. More women who were aged 26-30, living in the city and had no birth took FA at the right time. Also, women and their husbands with higher educational background were more likely to take FA at the right time and insist on taking every day. The increase of family income promoted FA insistence. Compared with women who gave birth, women without any history of pregnancy insisted on taking FA every day.

\section{Multivariate analysis of KAP}

From Table 3, it could be seen that age was the main factor that influenced the Attitude and Practice level of women during the periconceptional period. Compared to women aged $<25$ years, more women of $26-30$ years were willing to take FA in the right time (OR:2.21, 95\%CI:1.33-3.70) and insist on taking every day (OR: 2.30, 95\%CI:1.34-3.96), and were positively associated with high rates of premarital (OR:1.82,95\%CI:1.12-2.81) and pre-pregnancy examinations (OR:2.03, 95\%CI: 1.293.21). Besides, the knowledge pass rate was increased with education level whereas the significant association was only shown for senior high school or college category (OR: 1.69, 95\%:1.02-2.78). However, a negative association was found between women with birth experience and intake of FA consistently at the right time.

\section{Discussion}

Birth defects are influenced by different factors. Among these aspects, KAP is an integral part of primary prevention of birth defects. The attitude and practice of premarital and pre-pregnancy examinations, dietary habits, and drug intake of maternal women could affect their pregnancy outcomes. Moreover, KAP is not only an effective way to assess women's knowledge and behavior during pregnancy but also an essential means to promote and improve primary prevention measures. 
Li et al. BMC Pregnancy and Childbirth $\quad$ (2019) 19:326

Page 5 of 12

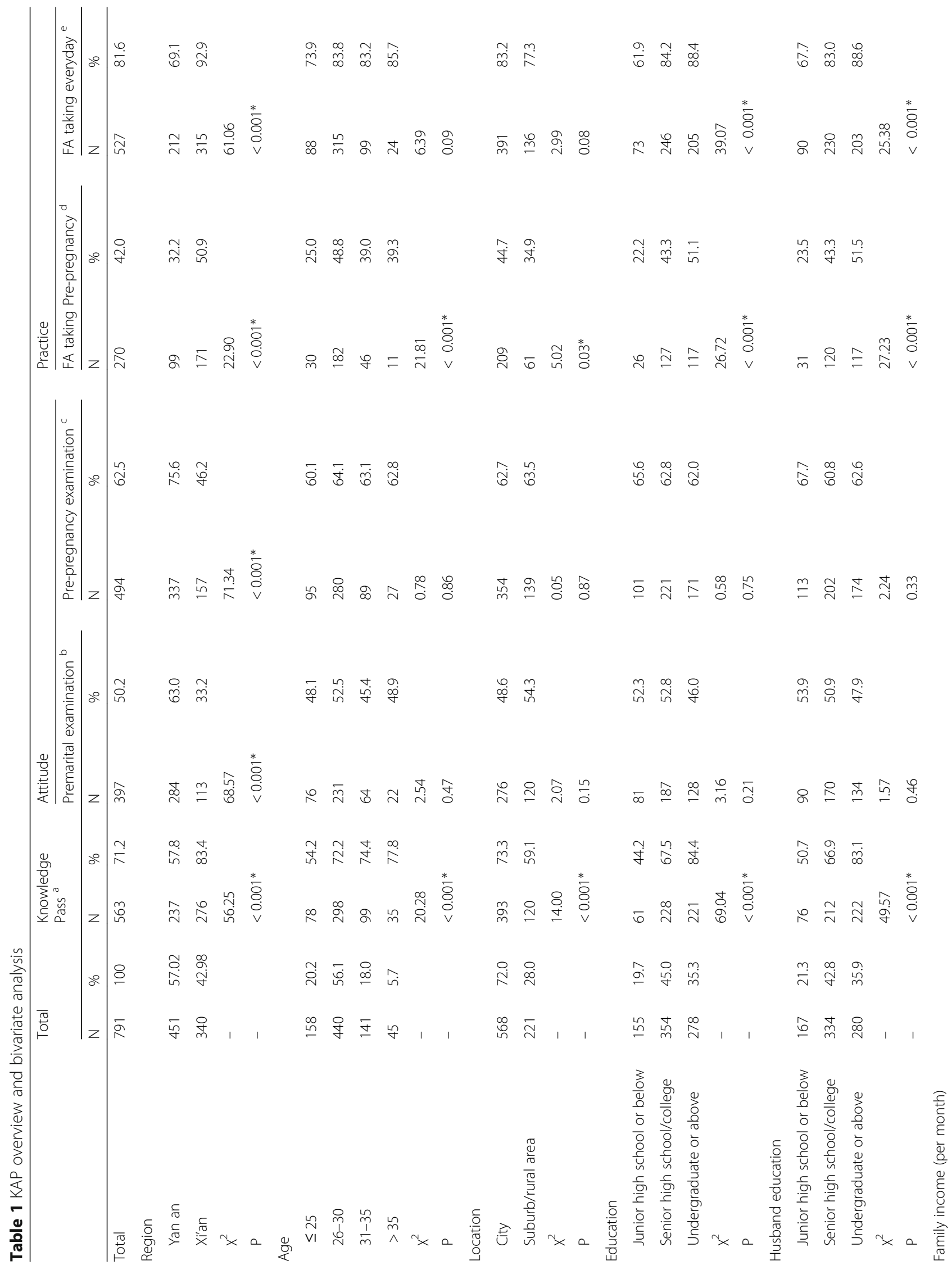


Li et al. BMC Pregnancy and Childbirth $\quad$ (2019) 19:326

Page 6 of 12

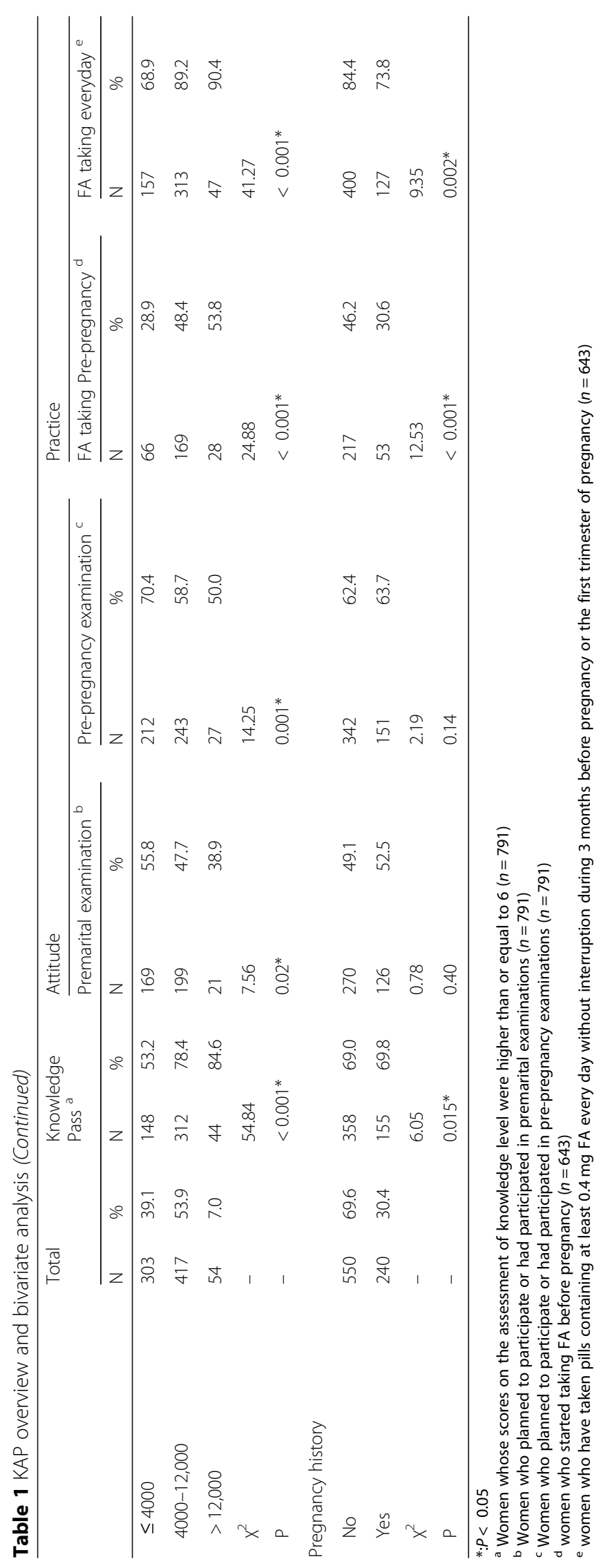


Li et al. BMC Pregnancy and Childbirth $\quad$ (2019) 19:326

Page 7 of 12

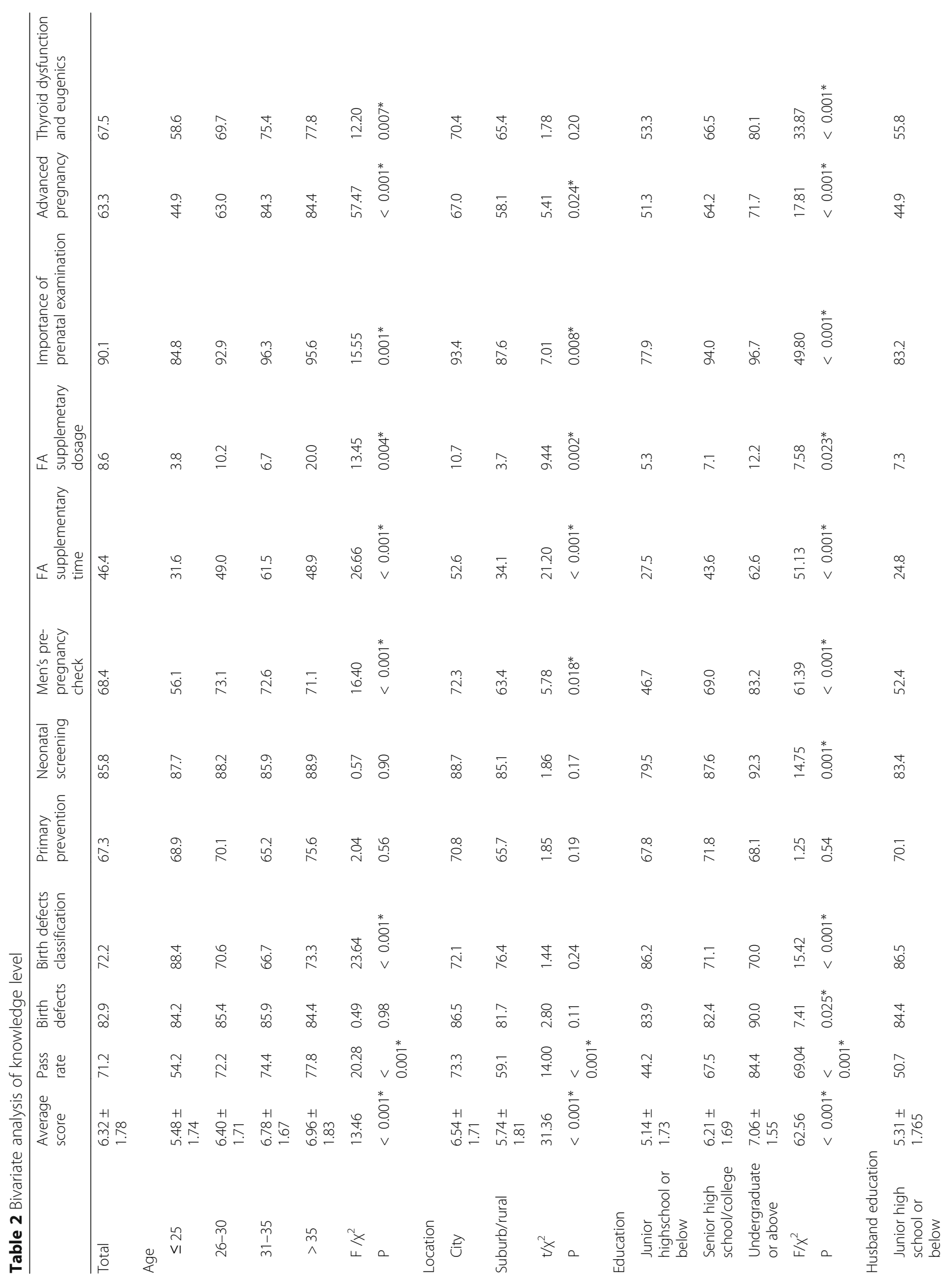




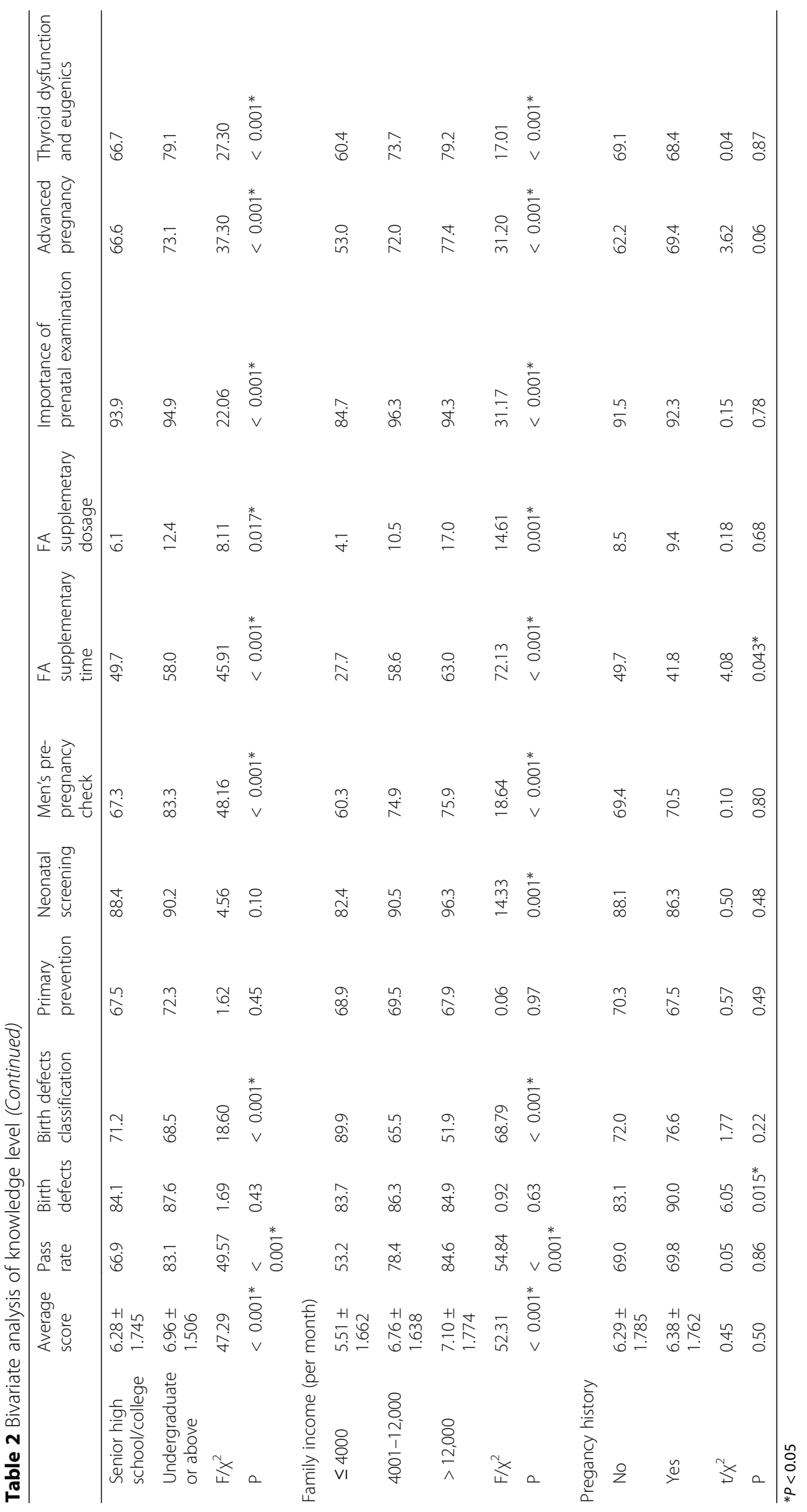


Table 3 Multivariate analysis of KAP

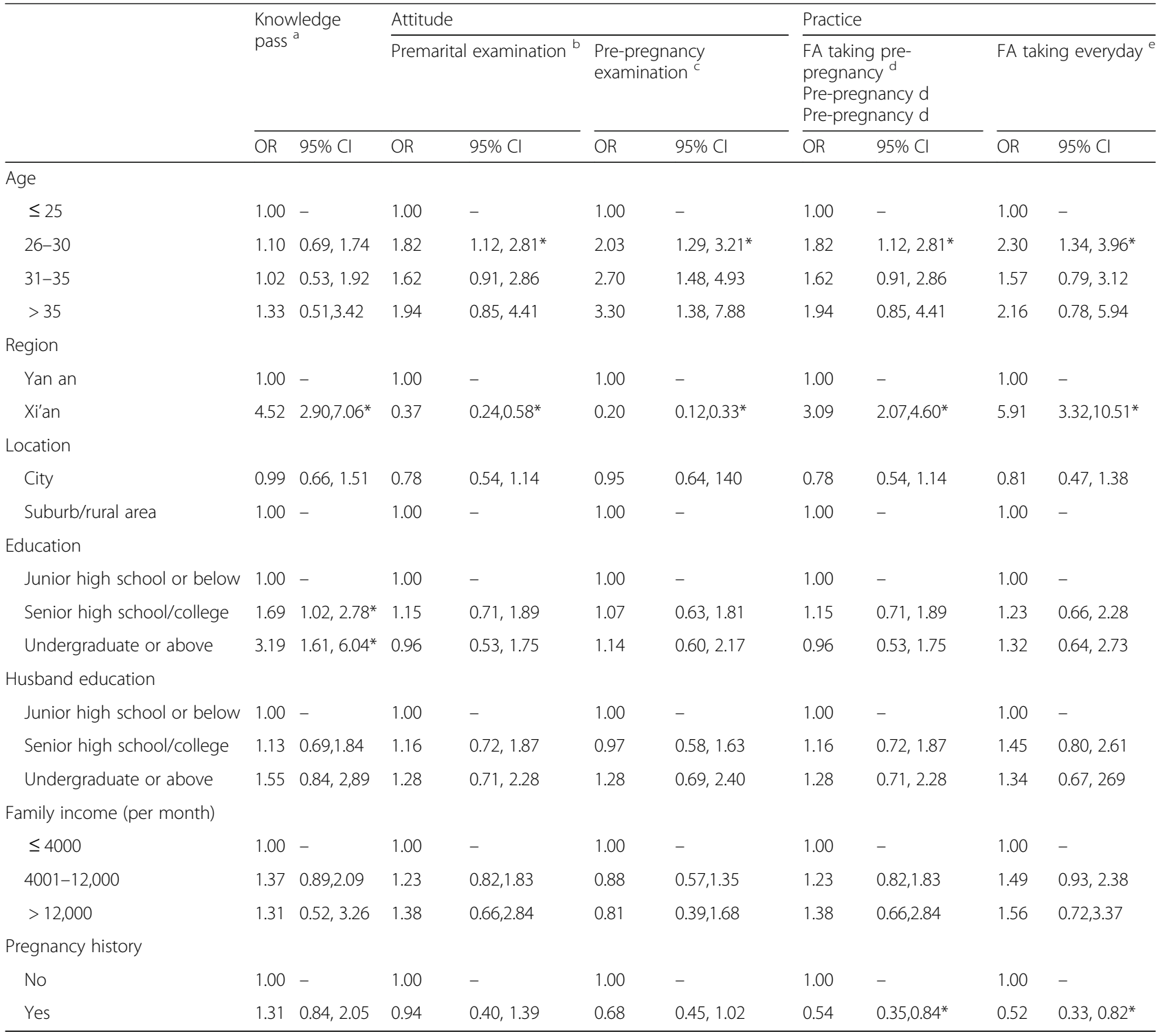

$* P<0.05$

${ }^{a}$ Women whose scores on the assessment of knowledge level were higher than or equal to 6 . $(n=791)$

${ }^{\mathrm{b}}$ Women who planned to participate or had participated in premarital examinations. $(n=791)$

' Women who planned to participate or had participated in pre-pregnancy examinations. $(n=791)$

${ }^{\mathrm{d}}$ women who started taking FA before pregnancy. $(n=643)$

${ }^{\mathrm{e}}$ women who have taken pills containing at least $0.4 \mathrm{mg}$ FA every day without interruption during 3 months before pregnancy or the first trimester of pregnancy. $(n=643)$

In this study, the knowledge level of the women at the childbearing age showed a lack of awareness in the total knowledge. The average score was lower than that of a previous survey conducted in Shaanxi, 2006 [20]. Besides, the knowledge level was significantly different in women of different ages, educational level, and location. It was proved that younger women from the rural area with a lower educational level and income more likely lacked knowledge on periconceptional healthcare. Also, in Shaanxi, Zhang found that pregnant women who had better education demonstrated higher awareness of prenatal care and birth defects prevention [18]. Therefore, combined with the previous studies, it was concluded that women at the periconceptional period have more cognition on prenatal care, but little improvement on preventive measures, especially taking FA during preand early-pregnancy was performed. Hence, several measures should be taken to strengthen the primary prevention knowledge, especially for rural areas, poor education and low-income women for promoting the understandability and multi-way health promotion education for improving the level of eugenic knowledge. 
These prevention measures should be particularly taken 3 months before pregnancy and the organogenesis during the pregnancy (week 3-8 of pregnancy for the CNS) for preventing birth defects [21].

In this study, the majority of women at the periconceptional period took FA during pregnancy, but less than half (37.9\%) took FA before pregnancy, and this was similar to the previous FA intake rate in Oregon, USA (33.2\%) [22], but was lower than Tianjin (40.4\%) located in the northeast of China [23]. In addition, 81.6\% of women insisted on taking FA, but only $37.9 \%$ of them took FA regularly for 3 months before pregnancy. So, it was concluded that most women are clear regarding the importance of FA and are willing to take FA; however, they had an insufficient understanding of how to take FA. Furthermore, women tended to take FA regularly if they were older, living in urban areas or had no children, and higher education. Similar results were also found in America and Denmark [24, 25]. Tamim also found that women who had less number of pregnancies took FA more regularly [26]. In this study, it was suggested that lower correct rate of FA supplementation (including starting time and supplementary dose) was consistent with lower knowledge awareness of FA supplementation, which was in agreement with other previous studies $[15,26]$. Kim et al. also showed that lower awareness on the effect of FA reduced the behavior of FA proper intake [15], and hence it was necessary to impart FA knowledge and benefits through health education or promotion, influencing the attitude and behavior of women during childbearing age. Other studies also demonstrated that planning for pregnancy had an impact on prenatal care, including maternal FA awareness, usage, and nutritional supplements [27, 28]. Hence, more specific FA intake knowledge and methods, especially the importance of pre-pregnancy FA usage, should be reinforced to the public with low education, low income and rural women.

As a protective factor, FA plays a crucial role in adverse pregnancy outcomes such as NTD and CHD prevention [10, 29]. However, low KAP level regarding the proper use of FA in women of Shaanxi may be a potential risk factor for causing these diseases, and similar results were found in the US [30]. Besides, the previous study found that the average rate of birth defects in rural areas was higher than that in urban areas in Xi'an [29]. In our study, women from rural areas and with poor education and family income tended to have lower KAP level, indicating that more attention should be paid on them to reduce the occurrence of adverse pregnancy outcomes. Nevertheless, our investigation on women at the childbearing age was just a cross-sectional study, and so the possible pregnancy outcomes were not obtained in the end. Whether the surveyed women with different KAP levels would directly influence the pregnancy outcomes still needs confirmation in the future.

The rate of premarital and pre-pregnancy examinations in our study was 50.2 and $62.5 \%$, respectively, which was still lower compared with other developed countries [19]. The three most common reasons for not participating in these examinations include "have done a physical examination, so don't need to undergo these examinations", "all families are healthy, so does not require these examinations", and "do not know how to undergo these examinations". It indicated that women at the childbearing age lacked awareness regarding the significance and importance of these examinations and prevention of pregnancy disorders. In China, since the mandatory premarital examination was abolished in 2003, the importance of regular check, especially before marriage and pregnancy examinations, has been diminished in public, followed by the concomitant declination of premarital examinations [31]. Studies in Zhejiang and Jiangsu showed that the proportion of pre-marital records was decreased from 71.3 to $14.6 \%$, and the rate of early pregnancy examinations was reduced from 64.0 to $50.0 \%$. Moreover, it was considered that with the increased popularity of public physical examinations in recent years, the rate of participation in these eugenic examinations was reduced. In terms of influential factors, it was found that the educational levels were related to the participation rate of premarital and pre-pregnancy examinations [18]. In consequence, more effective and comprehensive publicity should be carried out to focus on the necessity and importance of regular examinations of premarital and pre-pregnant periods as well as the differences between these checks and public physical examinations for women of childbearing age.

We need to acknowledge some limitations of this study. First of all, the loss of information was unavoidable during the follow-up of some participants because of changes in their phone number or residential address. In addition, we surveyed the KAP levels of 791 women at the periconceptional period in total, but some of their basic characteristic data were incomplete (e.g. the number of data obtained on age was 784), which resulted in some loss of information from the bivariate and multivariate analyses. Secondly, some of our respondents were enrolled from the hospitals, although the method of random sampling was adopted, the choice bias was challenging to avoid compared with the community population. Thirdly, the recall bias could not be eliminated completely due to limitations in the cross-sectional design, although a series of practical measures were used. Finally, while we included several important confounding factors, we cannot rule out potential residual confounding. For instance, we did not have access to individual characteristics such as ethnicity, floating population, and health insurance that may affect the outcomes. 


\section{Additional files}

Additional file 1: Table S1. Birth defects in Xi'an from 2003 to 2016. (DOCX $21 \mathrm{~kb}$ )

Additional file 2: Table S2. Ten closed choice questions to assess knowledge level section". (DOCX 22 kb)

\section{Abbreviations}

FA: Folic Acid; KAP: Knowledge, Attitude and Practice

\section{Acknowledgements}

We would like to thank all the women who participated in this survey and their families. We also are grateful to all the investigators for their contribution to data collection.

\section{Authors' contributions}

$L H, D L, W Y, M C C, L Z$ conceived the study; LH, DL analyzed, interpreted of data, LH, DL wrote the manuscript; LH, DL, LS, CQ, JX, HS, MZ collated data. All authors have been involved in revising the manuscript critically for important intellectual content; and they have given final approval of the version to be published.

\section{Funding}

This paper presents independent research and was supported by The Program of Xi'an Science and Technology [201805098YX6SF32(1)]; Key Science and Technology Program of Shaanxi Province (2019SF-100); The Center for Maternal and Child Health, Chinese Center for Disease Control and Prevention (2015FYJ002); Xi'an Health and Family Planning Commission (HX201549). The funding body was not involved in:the design of the study; the collection, analysis, interpretation of data; the writing the manuscript.

\section{Availability of data and materials}

The data generated and used in the analysis of this study are included in this published article. Additional data is available from the authors upon reasonable request.

\section{Ethics approval and consent to participate}

This research was approved by the Ethics Committee of Science of Medical center, First Affiliated Hospital of Xi'an Jiaotong University (No:XJTU1AF2017LSK-45). The written informed consent form was obtained from each participant who took part in this survey.

\section{Consent for publication}

Not applicable.

\section{Competing interests}

The authors declare that they have no competing interests.

\section{Author details}

'Department of Obstetrics and Gynecology, The First Affiliated Hospital of Xi'an Jiaotong University, Xi'an, Shaanxi, People's Republic of China. ${ }^{2}$ Department of Public Health and Community Medicine, Tufts University School of Medicine, Boston, Massachusetts, USA. ${ }^{3}$ Department of Epidemiology and Biostatistics, School of Public Health, Xi'an Jiaotong University Health Science Center, Xi'an, Shaanxi, People's Republic of China. ${ }^{4}$ Maternal and Child Health Hospital of Xi'an, Xi'an, Shaanxi, People's Republic of China.

\section{Received: 5 May 2018 Accepted: 28 August 2019}

Published online: 04 September 2019

\section{References}

1. Victora CG, Requejo JH, Barros AJ, Berman P, Bhutta Z, Boerma T, Chopra M, de Francisco A, Daelmans B, Hazel E, et al. Countdown to 2015: a decade of tracking progress for maternal, newborn, and child survival. Lancet (London, England). 2016;387(10032):2049-59.

2. Blencowe $H$, Cousens $S$, Oestergaard MZ, Chou D, Moller AB, Narwal R, Adler A, Vera Garcia C, Rohde S, Say L, et al. National, regional, and worldwide estimates of preterm birth rates in the year 2010 with time trends since 1990 for selected countries: a systematic analysis and implications. Lancet (London, England). 2012;379(9832):2162-72.

3. He C, Liu L, Chu Y, Perin J, Dai L, Li X, Miao L, Kang L, Li Q, Scherpbier R, et al. National and subnational all-cause and cause-specific child mortality in China, 1996-2015: a systematic analysis with implications for the sustainable development goals. Lancet Glob Health. 2017;5(2):e186-97.

4. Yang J, Cheng Y, Pei L, Jiang Y, Lei F, Zeng L, Wang Q, Li Q, Kang Y, Shen Y, et al. Maternal iron intake during pregnancy and birth outcomes: a crosssectional study in Northwest China. Br J Nutr. 2017;117(6):862-71.

5. Maternal and Child Health Surveillance: Birth defect surveillance 2014: Available from: http://www.mchscn.org/.

6. Wolf HT, Hegaard HK, Huusom LD, Pinborg AB. Multivitamin use and adverse birth outcomes in high-income countries: a systematic review and meta-analysis. Am J Obstet Gynecol. 2017;217(4):404.e401-30.

7. World Health Organization:Management of birth defects and haemoglobin disorders: report of a joint WHO-March of Dimes meeting, Geneva, Switzerland, 2006

8. Demaio AR, Dugee O, Amgalan G, Maximenco E, Munkhtaivan A, Graeser S, Kryger T, Oyunbileg J, Jousilahti P, De Courten M, et al. Protocol for a national, mixed-methods knowledge, attitudes and practices survey on noncommunicable diseases. BMC Public Health. 2011:11:961.

9. Sambo M, Lembo T, Cleaveland S, Ferguson HM, Sikana L, Simon C, Urassa $\mathrm{H}$, Hampson K. Knowledge, attitudes and practices (KAP) about rabies prevention and control: a community survey in Tanzania. PLoS Negl Trop Dis. 2014;8(12):e3310.

10. Bortolus R, Blom F, Filippini F, van Poppel MN, Leoncini E, de Smit DJ, Benetollo PP, Cornel MC, de Walle HE, Mastroiacovo P. Prevention of congenital malformations and other adverse pregnancy outcomes with 4.0 mg of folic acid: community-based randomized clinical trial in Italy and the Netherlands. BMC Pregnancy Childbirth. 2014;14:166.

11. Smith ER, Shankar AH, Wu LS, Aboud S, Adu-Afarwuah S, Ali H, Agustina R, Arifeen S, Ashorn P. Bhutta ZA. Modifiers of the effect of maternal multiple micronutrient supplementation on stillbirth, birth outcomes, and infant mortality: a meta-analysis of individual patient data from 17 randomised trials in low-income and middle-income countries. Lancet Glob Health. 2017:5(11):e1090.

12. Lian H, Ma D, Zhou SF, Li X. Knowledge and use of folic acid for birth defect prevention among women of childbearing age in Shanghai, China: a prospective cross-sectional study. Med Sci Monit. 2011;17(12):Ph87-92.

13. Amitai $Y$, Fisher $N$, Meiraz $H$, Baram N, Tounis $M$, Leventhal A Preconceptional folic acid utilization in Israel: five years after the guidelines. Prev Med. 2008;46(2):166-9.

14. Kannan S, Menotti E, Scherer HK, Dickinson J, Larson K. Folic acid and the prevention of neural tube defects: a survey of awareness among Latina women of childbearing age residing in Southeast Michigan. Health Promot Pract. 2007:8(1):60-8.

15. Kim MH, Han JY, Cho YJ, Ahn HK, Kim JO, Ryu HM, Kim MY, Yang JH, NavaOcampo AA. Factors associated with a positive intake of folic acid in the periconceptional period among Korean women. Public Health Nutr. 2009; 12(4):468-71.

16. Sato $Y$, Nakanishi T, Chiba T, Umegaki K. Attitudes of pregnant Japanese women and folic acid intake for the prevention of neural tube defects: a nationwide internet survey. Nihon Koshu Eisei Zasshi. 2014;61(7):321-32.

17. Yang W, Zeng L, Cheng Y, Chen Z, Wang X, Li X, Yan H. The effects of periconceptional risk factor exposure and micronutrient supplementation on birth defects in Shaanxi Province in Western China. PLoS One. 2012;7(12):e53429.

18. Zhang R, Li S, Li C, Zhao D, Guo L, Qu P, Liu D, Dang S, Yan H. Socioeconomic inequalities and determinants of maternal health services in Shaanxi Province, Western China. PLoS One. 2018;13(9):e0202129.

19. Boulet SL, Parker C, Atrash H. Preconception care in international settings. Matern Child Health J. 2006;10(5 Suppl):S29-35.

20. Yang $W$, Yang L, Liu L, Li Y, Wu J. An investigation and analysis of KAP on birth defects of periconceptional women in Xi'an areas. Chin J Woman Child Health Res. 2011;22(1):36-9 In Chinese.

21. Canfield MA, Honein MA, Yuskiv N, Xing J, Mai CT, Collins JS, Devine O, Petrini J, Ramadhani TA, Hobbs CA, et al. National estimates and race/ ethnic-specific variation of selected birth defects in the United States, 19992001. Birth Defects Res A, Clin Mol Teratol. 2006;76(11):747-56.

22. Rosenberg KD, Gelow JM, Sandoval AP. Pregnancy intendedness and the use of periconceptional folic acid. Pediatrics. 2003;111(5 Pt 2):1142-5. 
23. Yan J, Liu Y, Cao L, Zheng Y, Li W, Huang G. Association between duration of folic acid supplementation during pregnancy and risk of postpartum depression. Nutrients. 2017;9(11):1206.

24. Olsen SF, Knudsen VK. Folic acid for the prevention of neural tube defects: the Danish experience. Food Nutr Bull. 2008;29(2 Suppl):S205-9.

25. Temel S, Erdem O, Voorham TA, Bonsel GJ, Steegers EA, Denktas S.

Knowledge on preconceptional folic acid supplementation and intention to seek for preconception care among men and women in an urban city: a population-based cross-sectional study. BMC Pregnancy Childbirth. 2015;15:340.

26. Tamim H, Harrison G, Atoui M, Mumtaz G, El-Kak F, Seoud M, Yunis K. Preconceptional folic acid supplement use in Lebanon. Public Health Nutr. 2009;12(5):687-92.

27. Stockley L, Lund V. Use of folic acid supplements, particularly by lowincome and young women: a series of systematic reviews to inform public health policy in the UK. Public Health Nutr. 2008;11(8):807-21.

28. Arslan Ozkan I, Mete S. Pregnancy planning and antenatal health behaviour: findings from one maternity unit in Turkey. Midwifery. 2010;26(3):338-47.

29. van Beynum IM, Kapusta L, Bakker MK, den Heijer M, Blom HJ, de Walle HE. Protective effect of periconceptional folic acid supplements on the risk of congenital heart defects: a registry-based case-control study in the northern Netherlands. Eur Heart J. 2010;31(4):464-71.

30. Canfield MA, Przybyla SM, Case AP, Ramadhani T, Suarez L, Dyer J. Folic acid awareness and supplementation among Texas women of childbearing age. Prev Med. 2006;43(1):27-30.

31. Hesketh T. Getting married in China: pass the medical first. BMJ. 2003; 326(7383):277-9.

\section{Publisher's Note}

Springer Nature remains neutral with regard to jurisdictional claims in published maps and institutional affiliations.

Ready to submit your research? Choose BMC and benefit from:

- fast, convenient online submission

- thorough peer review by experienced researchers in your field

- rapid publication on acceptance

- support for research data, including large and complex data types

- gold Open Access which fosters wider collaboration and increased citations

- maximum visibility for your research: over $100 \mathrm{M}$ website views per year

At $\mathrm{BMC}$, research is always in progress.

Learn more biomedcentral.com/submissions 